\title{
ANAESTHESIA TIME/DOSE CURVES IX: THE USE OF HYDROMORPHONE IN SURGICAL ANAESTHESIA AND POSTOPERATIVE PAIN RELIEF IN COMPARISON TO MORPHINE*
}

\author{
M. KeEri-Szanto
}

As LONG AS PATIENTS PREFER general anaesthesia for their operations, anaesthetists will remain committed to supplement nitrous oxide (a safe but only partial anaesthetic at atmospheric pressure) with some other agent for most interventions. A host of such substances is available: halogenated vapours, thiobarbiturates, muscle relaxants, butyrophenons and various narcotics, to mention just a few. Among the latter, for reasons to be set out below, it appeared of interest to investigate the use of hydromorphone, a semisynthetic morphine derivative that has seen service as a potent pain-killer for more than half a century. This report deals with our findings during and following extensive surgery.

\section{Material and Methons}

Patients included in this study were unselected except for being assigned to the writer, scheduled for operations expected to require more than three hours of anaesthesia and being free of frank cardiovascular collapse at the time of induction. All ages over 7 years, all operations, except cardiac surgery, and all grades of anaesthetic risks, including major emergency procedures, are represented. The need for premedication was discussed with the patient and in the (roughly) 40 per cent of the cases where it was deemed advantageous, hydromorphone 1-2 mg was prescribed sub-cutaneously 90 minutes before the patient's estimated time of arrival in the operating suite. This dose was included in subsequent calculations. Vagolytic agents were not employed.

Anaesthesia was induced by intravenous increments of hydromorphone and the simultaneous exhibition of 70 per cent $\mathrm{N}_{2} \mathrm{O}$. The characteristic signs sought for were extinction of the eyelid reflex, bradycardia, increased digital pulse volume and tolerance of manually assisted ventilation. Pancuronium 4-6 mg was injected intravenously at this stage and 180 seconds later the trachea was sprayed with topical lidocaine and intubated. The patient was immediately connected to a ventilator set to deliver 10 to 12 times 800 to $1200 \mathrm{ml}$ in a Bain circuit., ${ }^{1,2}$ The fresh gas inflow was set initially at $3000 \mathrm{ml} / \mathrm{m}^{2}$ (calculated from tables). In reviewing the level of anaesthesia, sweating, hypertension, tachycardia, or fighting the respirator were considered signs of insufficient depth and this was corrected by additional intravenous increments of hydromorphone. Although the fresh gas

"From the Department of Anaesthesia, Victoria Hospital, London, Ontario, N6A 4G5.

M. Keeri-Szanto, M.D., F.R.C.P.(C), F.C.P., Clinical Associate Professor of Anaesthesia, University of Western Ontario.

Material for this study (Dilaudid(B) was graciously supplied by Dr. M. Grozier of Knoll Pharmaceuticals of Whippany, New Jersey, U.S.A. 07981. Read in part at the I World Congress on Pain, Firenze, Italy, September 1975 and at the VI World Congress of Anesthesiology, Mexico City, April 1976. 
inflow was occasionally adjusted in the course of the operation when it became apparent that the patient's metabolic requirements were outside the normal range, the $\mathrm{F}_{\mathrm{N}_{2} \mathrm{O}}$ was kept unchanged. Muscle relaxants were reserved for providing a convenient surgical field.

Monitoring during operation included a display of digital pulse volume, nasopharyngeal temperature, $\dot{\mathrm{V}}_{\mathrm{CO}_{2}}$ and mixed expired $\mathrm{P}_{\mathrm{Co}_{2}}$. None of these showed changes that we considered peculiar to hydromorphone and their outcome will not be reported in detail here. No restriction was placed on the quantity or composition of fluids administered during the operation: all patients received at least 500 $\mathrm{ml}$ of 5 per cent dextrose, while the bulk of the fluids was given as lactated Ringer's solution. Blood was administered in the operating room, usually when the estimated blood loss exceeded $1000 \mathrm{ml}$. The transfusion of several units was commonplace; one patient required 16 units before the end of the operation. Controlled hypotension produced by a trimetaphan drip was employed in twelve cases of extensive cervico-maxillo-facial operations. In many, though not all patients, blood gases were monitored hourly. These were invariably within normal range. A careful record was kept of the size and timing of each increment of hydromorphone received by the patient.

Towards the end of the operation curarization was reversed if this appeared necessary and the flow of fresh gases into the system was diminished without changing the rate and depth of ventilation. Oxygenation was maintained in this fashion while allowing $\mathrm{CO}_{2}$ to build up gradually. The post-operative ventilatory requirements of the patient were assessed, particularly with regard to the heat deficit usually incurred during extensive operations in an air-conditioned operating room. ${ }^{3}$ The indications for post-operative respiratory assistance, lasting approximately as long again as the anaesthesia time, were drawn widely: old age, substantial haemodilution, cardiorespiratory problems before operation, a core temperature drop as small as $0.5^{\circ} \mathrm{C}$ made us delay extubation, continue mechanical respiratory assistance, and even to administer additional increments of hydromorphone if the patient appeared uncomfortable at a time when his vital functions had not yet returned to the desired level of homeostasis.

The narcotic antagonist levallorphan was administered intravenously to five patients who, in the writer's opinion, exhibited undue respiratory depression at the end of operation. Nasal oxygen, 31 per minute was given for several hours as a routine measure to all patients following operations lasting longer than three hours.

In patients who were retained in the critical care areas of the hospital, postoperative discomfort was treated by continued small intravenous increments of hydromorphone. Such increments were provided promptly on request and the patients were repeatedly instructed to make free use of them until they felt "comfortable" instead of "not bothering the nurses." The usual dose was $0.2 \mathrm{mg}$ and their exact size and timing were carefully noted.

From the amount and timing of hydromorphone administered during surgery, a time/dose curve of the drug was constructed for each patient. The slope and intercept of this curve yielded the drug's therapeutic half-life (or its therapentic elimination rate constant) in that individual (reference 4 and Figure 1 in this article). Armed with the rate constant one could then calculate from the main- 


\section{TOTAL $\operatorname{DOSE}(y)$ \\ DRUG REQUIREMENTS DURING WHIPPLE PROCEDURE, $440 \mathrm{~min}, 851$}

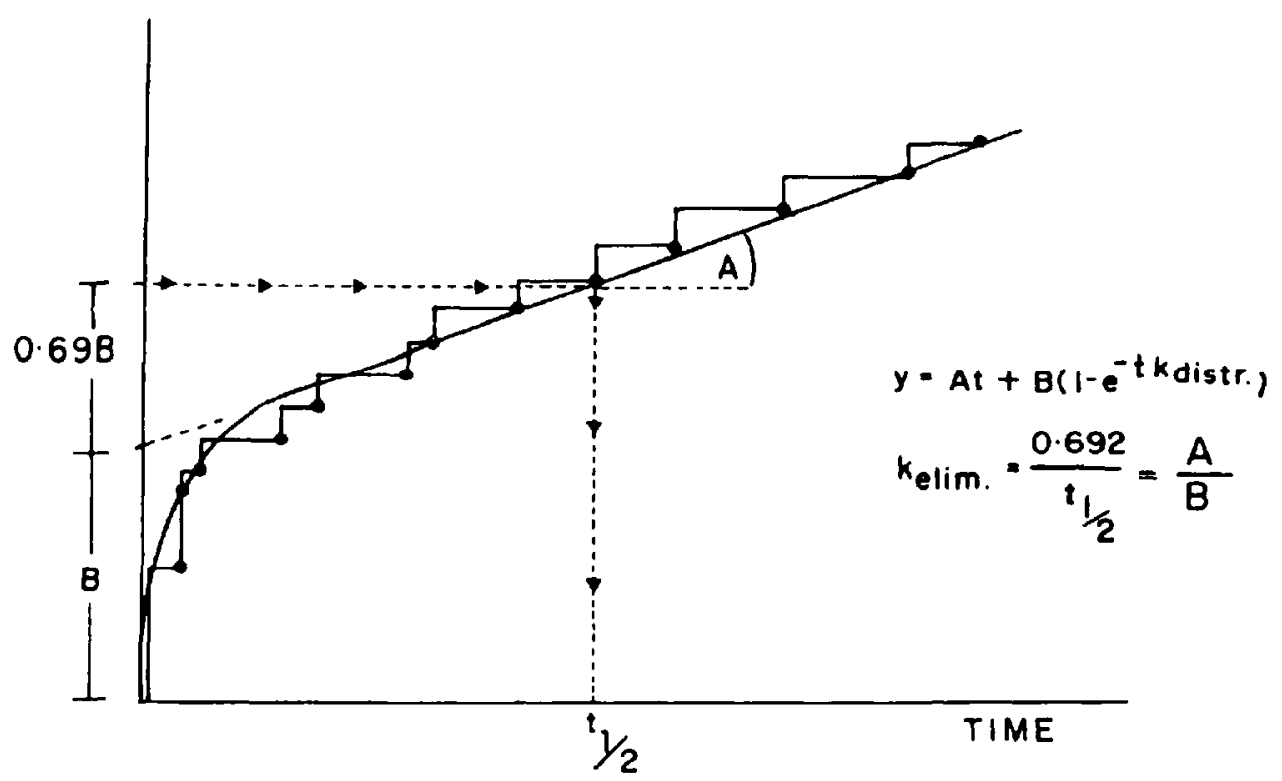

FIgUre 1: An example of time/dose curve construction from the timing and size of intravenous anaesthetic increments in the course of an operation lasting longer than 7 hours. The linear portions intercept with the $\mathrm{Y}$ axis denotes the loading portion (B) of the total amount (Y) required for the maintenance of a steady level of anaesthesia. The ratio of maintenance rate (A) to loading dose (B) equals, by definition the elimination rate-constant for the drug in that subject $\mathrm{k}_{\mathrm{e} I \mathrm{In}}=\mathrm{A} / \mathrm{B}$. The $\mathrm{t}$ co-ordinate of $\mathrm{Y}=1.692 \mathrm{~B}$ corresponds to the functional half-life of the drug at the target site according to the law of first-order kinetics $t_{*}=0.692 / \mathrm{k}_{\mathrm{e} 1 \mathrm{~m} \mathrm{~m}}$. Note that the first point in the curve is $t=0, Y=0$ and each increment is plotted against the time when its effect has just worn off (the last point is plotted against the moment of return of consciousness). Such an arrangement minimizes the effect of operator bias and of the occasional ill-timed injection on the overall shape of the curve. (Reproduced with permission from Brit. J. Anaesth. $46: 918,1974$.

tenance rate set post-operatively by the patient himself, the amount of active drug continuously maintained in his body that would just prevent discomfort during the recovery period by using the formula $B=A / K_{t}$ (Figure 1 ). It was also possible to tabulate the individual loading doses, maintenance rates and rate constants to establish the distribution and centroidal tendency of each parameter. These values could then be compared with data obtained for other drugs under the same circumstances.

\section{Results}

Figure 1 shows a typical time/dose curve construct, indicating the way in which the loading dose, the maintenance rate, the therapeutic half-life, and the therapeutic rate-constant can be derived from the observed data.

Table I compares information about hydromorphone obtained in 70 subjects with data collected earlier by our group from 44 subjects with morphine under the same circumstances. ${ }^{4}$ Values representing the 5, 50 and 95 percentile level of dis- 


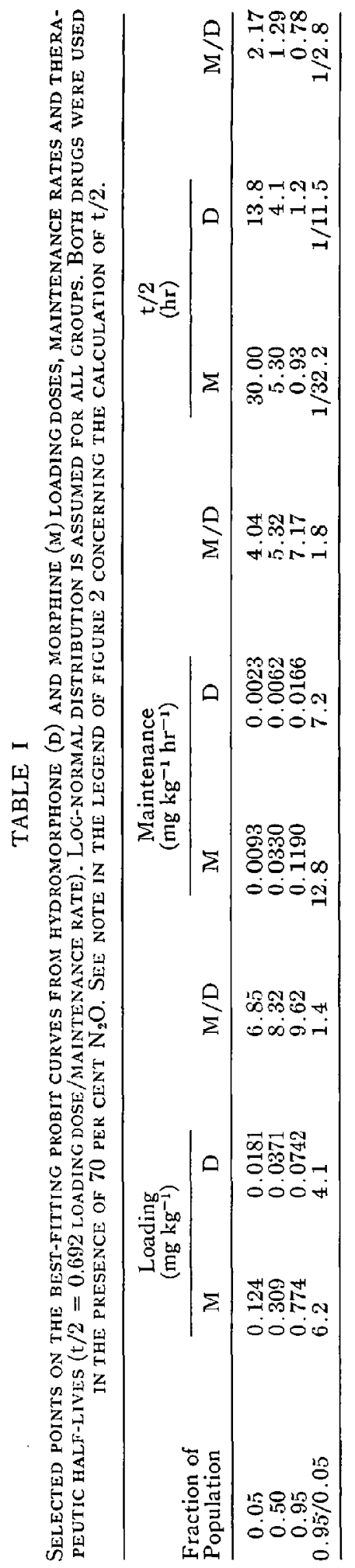




\section{HYDROMORPHONE - $\mathrm{N}_{2} \mathrm{O}$ (70 subjects)}

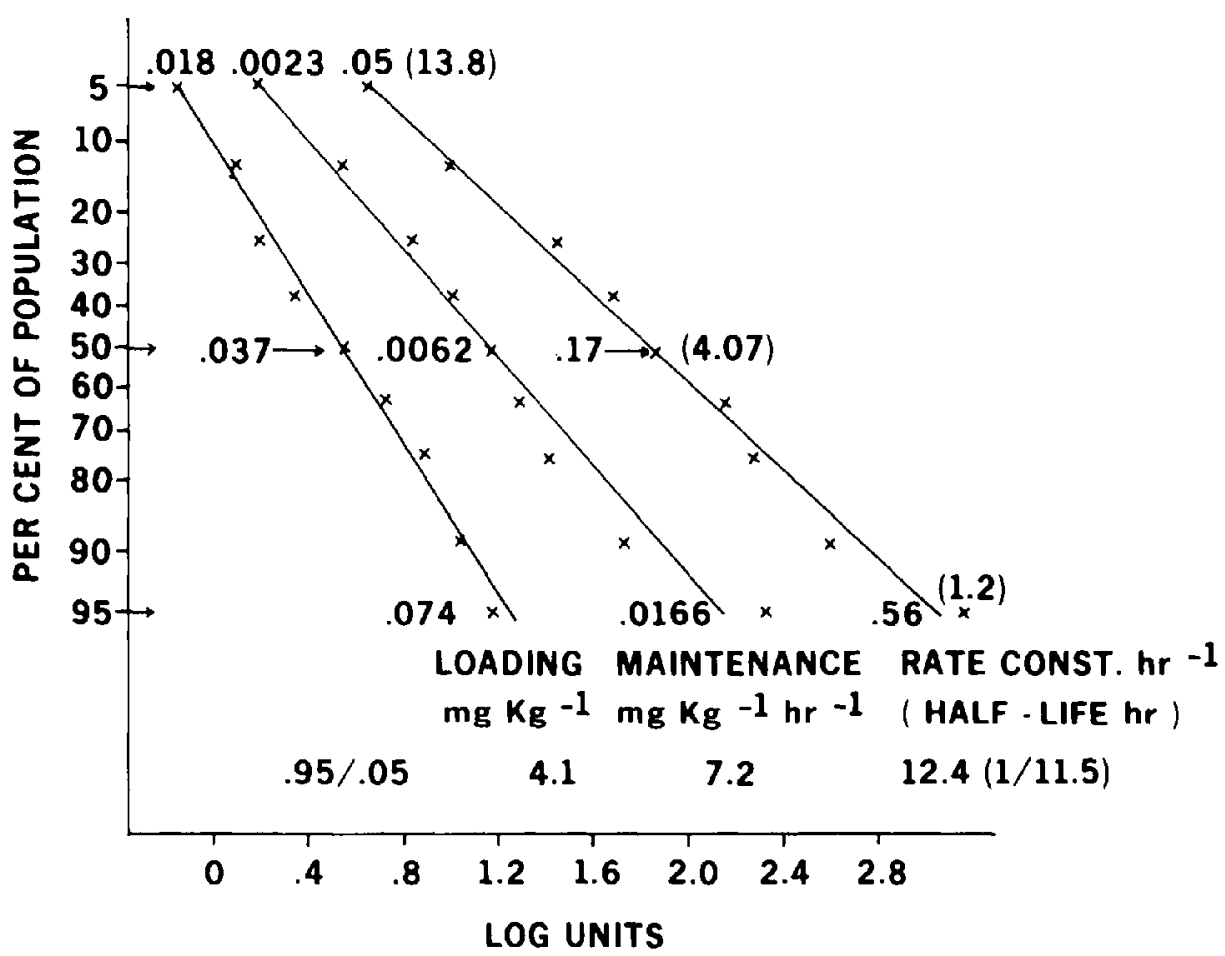

Figure 2. The distribution of natural logarithms of the loading dose of hydromorphone, maintenance rate and therapeutic rate constant or half-life in 70 subjects. The observed values corresponding to $5,12.5,25,37.5,50,62.5,75,87.5$ and 95 per cent of the population are illustrated. The best-fitting straight line through these points has been determined after probit transformation. The points from the line corresponding to 5,50 and 95 per cent are set out in numbers along with data about the $0.95 / 0.05$ ratio reflecting the observed variance of each parameter. Note that the variance includes changes attributable to the simultaneous exhibition of $\mathrm{N}_{2} \mathrm{O}$ and that the rate constants and half-lives were calculated individually for each patient. This will explain the discrepancy between the values shown in the graph and those that could be calculated from the equation presented in Figure 1.

tribution of both drugs are presented. Log normal distribution and first-order kinetics are assumed to apply. The hydromorphone data are shown in more detail as probit curves in Figure 2.

Figure 3 presents, also in the form of probit curves, the distribution of time intervals between the last increment of hydromorphone administered in the course of operation and the first post-operative request for pain relief. We also show in two separate curves the calculated fraction of the anaesthetic loading dose required for patient comfort during recovery following intraperitoneal and extraperitoneal operations.

\section{COMMENT}

The construction of time/dose curves was analyzed in several earlier publications from this department ${ }^{4,5}$ and is illustrated once again in Figure 1. It is a convenient 


\section{CDC FOLLOWING HYDROMORPHONE \\ IN 30 PATIENTS SUBJECTED TO MAJOR SURGERY}

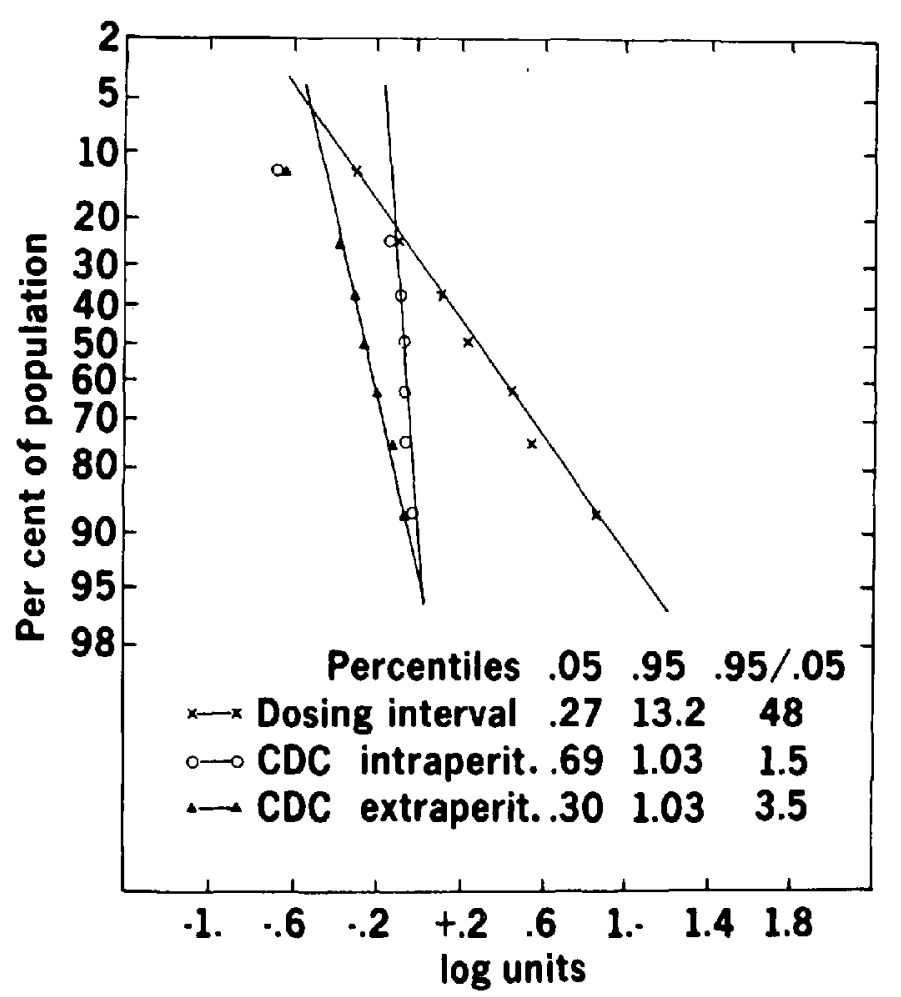

Figure 3. Distribution of the natural logarithms of the initial dosing interval (in hours) following hydromorphone- $\mathrm{N}_{2} \mathrm{O}$ anaesthesia as well as the calculated critical drug content (CDC) in the patient's body that will just prevent discomfort during the post-operative period. The latter is expressed as natural logarithm of the retained fraction of the loading dose and separate lines are fitted to data collected following extraperitoneal and intraperitoneal operations. Cf. legend of Figure 2 for the details of the calculation.

and in its simplicity a surprisingly precise procedure for collecting pharmacological and pharmacokinetic information directly from clinical populations. Among its advantages one might cite in the present context that by comparing loading doses calculated from such curves instead of the observed total drug requirements over a certain period of time, the relative potency of two agents with different therapeutic half-lives may be obtained without elaborate calculations. It should be clear by reflection alone that if two drugs are inactivated in the body at different rates, a statement about their relative potency can be interpreted only if the time of comparison is also available or, as in the present case, if the data can be extrapolated to zero time. In these terms, Table I shows that the median loading dose of morphine is 8.3 times greater than that of hydromorphone. This by itself would not make hydromorphone a more desirable agent unless it could also be shown that its therapeutic index is greater (this has not been tested in our study) or that 
it shows less variability and therefore better predictability in its action. Since data on responsiveness to different drugs are generally distributed in a log-normal fashion we have elected to take the mid-90 per cent variance as a measure of their centroidal tendency instead of the customary standard deviation: the ratio of the loading dose of hydromorphone that is effective in 95 per cent of the population over the one that is effective in only 5 per cent turns out to be 30 per cent smaller than that of morphine. The difference is even more marked when the variance in the therapeutic half-lives of the two agents is compared. Hydromorphone displays only 35 per cent of the observed variance of morphine. We believe that these findings have practical significance. The problem facing the therapist as he starts the treatment of a patient whose response to a given drug has not yet been established is how to bring previous experience with others to bear on the new candidate. This task will obviously be simplified if one deals with a drug whose action is qualitatively as well as quantitatively more uniform than when large individual differences in response are to be anticipated. The mid-90 percentile variance disregards the extreme 10 per cent of the sample population, which adds up to a sizeable number of patients in clinical practice. Yet, even within these limits, we find a twelve-fold difference in the therapeutic half-life of hydromorphone and a thirty-two-fold difference with morphine. Under these circumstances it is foolhardy to expect that simple schedules and dosing strategies will satisfy the entire patient population without exposing some patients to the dangers of over-dosage or under-dosage. We have commented in detail on this in an earlier report. ${ }^{6}$

The data in Figure 3 have interesting implications beyond the use of hydromorphone for pain relief. When surgical anaesthesia is established with $\mathrm{N}_{2} \mathrm{O}$ and a narcotic, at the end of the operation $\mathrm{N}_{2} \mathrm{O}$ will dissipate rapidly and the narcotic will be inactivated at a slower rate. At the same time, the sensory input that forms the basis of the patient's subjective sensation of pain will also be substantially reduced in comparison with the levels prevailing during the operation. The net result of all these simultaneous changes will be the reasonably prompt return of consciousness and an initial period of comfort that will eventually yield to the sensation of postoperative pain, indicated to the observers by various signs, including a request for pain-relief. It is common knowledge that very large variations exist in the length of pain-free intervals following surgery. This has been attributed to the kind of anaesthetic employed and to the nature of the operation, but most particularly to the large individual differences in pain tolerance. The distribution of the initial dosing intervals in the figure following the use of a standardized anaesthetic technique for major operations certainly supports such a contention; the mid- 90 percentile variance is 48 -fold, ranging from 25 minutes to 17.5 hours. A very different picture emerges, however, when the same data are analyzed in terms of what fraction of the surgical loading dose of the narcotic was still present in the patient's body when discomfort set in. In extraperitoneal operations that were less homogenous as far as altered postoperative sensory input is concerned (craniotomies had to be compared with back operations or renal surgery or extensive procedures on the limbs), the comparable variance was only 3.5 -fold, ranging from 0.29 to 1.03 of the original surgical loading dose. In the more 
homogeneous group of intraperitoneal operations, the variance was further diminished to 1.5 , ranging from 0.65 to 1.03 of the loading dose. The surgical loading dose is established by relatively objective criteria during a period when the patient is unconscious. Its scatter is probably related to such factors as size of the fat deposits, permeability of the blood-brain barrier, the patient's hydration, and the like: it may be taken to be free of psychological modulation. The fact that a reasonably constant fraction of this figure is then associated by the patient with the threshold separating postoperative comfort from discomfort indicates to us that, at least in this category of pain, physiological and pharmacodynamic considerations far outweigh psychological factors in determining drug requirements. It is perhaps of equal interest that in this series we could again confirm earlier observations ${ }^{7}$ that the relationship between drug requirements and the therapeutic half-life of the agent in the individual becomes obscured when the drug is given by any other than the intravenous route. This is likely due to the imposition of additional variables associated with the degree and rate of absorption.

\section{SUMMARY}

Seventy unselected subjects were anaesthetized for major surgical operations with intravenous hydromorphone, nitrous oxide and muscle relaxants as required. The results were compared with earlier observations made with morphine under similar conditions on 44 other subjects from the same hospital population. Hydromorphone was found to be 8.5 times as potent as morphine in terms of the median surgical loading dose, and its median therapeutic half-life was 4.07 hours against morphine's 5.28 hours. It proved to be superior to morphine in its greater consistency of action. The mid-90 per cent variance of its loading dose was 30 per cent less and the same variance of its therapeutic half-life was 65 per cent less than that of morphine. All the differences were statistically significant or highly significant. Observations concerning the fraction of the surgical loading dose of hydromorphone required by the patients to prevent post-operative discomfort also revealed great consistency. This is taken to indicate that psychological factors play only a subordinate role in modulating the intensity of postoperative pain.

\section{RÉSUMÉ}

Chez 70 malades soumis à une chirurgie majeure, l'Hydromorphone a été employée en injection intraveineuse comme complément à une anesthésie au protoxyde d'azote associé au curare. Les courbes dose/durée ont été comparées à celles établies auparavant selon un protocole identique chez 44 malades anesthésiés à la Morphine. D'après les doses moyennes d'induction, l'Hydromorphone posséderait 8.5 fois la puissance de la Morphine et sa demi-vie thérapeutique moyenne serait de 4,07 heures (Morphine 5,28 heures). Elle est apparue d'action plus uniforme que la Morphine : par rapport à celle de la Morphine, la variance de la dose d'induction pour les observations se situant entre le 5e et le $95 \mathrm{e}$ centile (mid-90 pour cent variance) était moindre du tiers; analysée de la même façon, la variance de la demi-vie thérapeutique était de 65 pour cent moindre que celle de la Morphine. Toutes les différences étaient ou significatives ou très significatives. La dose néces- 
saire pour prévenir l'inconfort post-opératoire, exprimée en pourcentage de la dose d'induction chirurgicale, s'est aussi montrée beaucoup plus uniforme : nous en déduisons que les facteurs psychologiques ne jouent qu'un rôle de second plan dans la modulation de l'intensité de la douleur post-opératoire.

\section{REFERENCES}

1. Bain, J.A. \& Spoerel, W.E. A streamlined anaesthetic system. Canad. Anaesth. Soc. J. 19: 426-435 (1972).

2. Keeni-Szanto, M. Isokapnic ventilation during surgical operations: description of equipment and first results. Anesth. and Analg. 49: 406-412 (1970).

3. Keeni-Szanto, M. Themometry during surgery: an index of metabolic competence. Presented at the Annual Meeting of the Canadian Anaesthetists' Society, Kingston, Ontario, June 1975.

4. KeEni-SzaNto, M. The mode of action of promethazine in potentiating narcotic drugs. Brit. J. Anaesth. 46: 918-924 (1974).

5. Keert-Szanto, M. Drug consumption during thiopentone-nitrous oxide-relaxant anaesthesia: the preparation and interpretation of time/dose curves. Brit. J. Anaesth. 32: $415-423(1960)$.

6. Keeri-Szanto, M. \& Heaman, Susan. Post-operative demand analgesia. Surg. Gyn. \& Obs, 134: 647-651 (1972).

7. Keeri-Szanto, M. The evolution and titration of post-operative pain. Proceedings A.S.A. Annual Meeting, 1974. 